\title{
Comparative Assessment between Ibuprofen, Chewing Gum, and Bite Wafers in Pain Control Following First Arch Wire Placement in Orthodontic Patients
}

\author{
Eman I Al Shayea
}

\begin{abstract}
Purpose: This study aimed to investigate the effectiveness of using bite wafers and chewing gum in relieving pain after the activation of the first arch wire among Saudi orthodontic patients and evaluating them in comparison with ibuprofen use. Furthermore, the study investigated the effect of chewing gum and plastic wafers on the frequency of orthodontic appliance breakage.

Materials and methods: A total of 105 female patients aged 15-35 years, undergoing maxillary and mandibular fixed appliance treatment were classified randomly into three groups of 35 each. In each group, the patients were given one of the following treatments immediately after the placement of the first arch wire, every 8 hours for 1 week as needed: ibuprofen $(400 \mathrm{mg}$ ), or a viscoelastic bite wafer, or chewing gum. A visual analog scale was given to the patients to record their pain perception following initial arch wire placement. In addition, the patients were asked to report any incidence of detached brackets while using the above methods. Data were analyzed using analysis of variance (ANOVA).

Results: No statistically significant differences were found in pain perception at any time interval among the three groups. The pain experienced at bedtime and 24 hours after wire placement among different groups in the present study was found to be slightly higher with maximum intensity and the pain perception finding at different time intervals within each pain relief method was statistically significant $(p=0.000$, $p<0.05)$. Furthermore, ANOVA results demonstrate no significant differences in bracket detachment between the groups $(p=0.20, p<0.05)$. Conclusion: The use of bite wafers and chewing gum was effective and comparable to ibuprofen use for pain relief following the initial activation of fixed orthodontic appliances among Saudi orthodontic patients. In addition, the study found no clinically or statistically significant differences in bracket detachment between the groups.

Clinical significance: The nondrug modalities of controlling pain such as chewing gum and/or bite wafers can be used as an alternative to ibuprofen use following the first activation of fixed orthodontic appliances.

Keywords: Bite wafers, Chewing gum, Ibuprofen, Orthodontic treatment, Pain control.

The Journal of Contemporary Dental Practice (2020): 10.5005/jp-journals-10024-2804
\end{abstract}

\section{InTRODUCTION}

Pain is the most common complaint among patients receiving orthodontic treatment, especially after the activation of fixed or removable orthodontic appliances. In addition, pain has been considered an important factor for determining treatment acceptance, a deterrent to patient compliance, and the principal reason for treatment discontinuation. ${ }^{1,2}$ Pain is a subjective response that shows large individual variations related to several factors, such as the patient's emotional state, age, gender, pain threshold, and the magnitude of orthodontic force. ${ }^{1,3}$ Orthodontic pain commonly results from different abnormalities in the compressed periodontal ligaments (PDL) such as ischemia, inflammation, and edema during the application of orthodontic force to teeth. This triggers the release of certain mediators such as prostaglandins and initiates an inflammatory reaction, eventually causing pain. ${ }^{4,5}$ Orthodontic pain usually begins 2-3 hours after appliance fitting and persists for the following 5-7 days. ${ }^{6,7}$ According to Sergl et al., ${ }^{8}$ patients undergoing fixed orthodontic treatment have reported greater pain and discomfort than patients with removable plates. Among various age groups, children report less pain compared to adults. In the same age groups, females report greater pain experience than males. ${ }^{9}$

In order to enhance patient compliance and cooperation during the course of the treatment, controlling the pain during orthodontic tooth movement is required. Different studies
Division of Orthodontics, Department of Pediatric Dentistry and Orthodontics, College of Dentistry, King Saud University, Riyadh, Kingdom of Saudi Arabia

Corresponding Author: Eman I Al Shayea, Division of Orthodontics, Department of Pediatric Dentistry and Orthodontics, College of Dentistry, King Saud University, Riyadh, Kingdom of Saudi Arabia, Phone: +966 505420838, e-mail: e_shayea@hotmail.com

How to cite this article: Al Shayea El. Comparative Assessment between Ibuprofen, Chewing Gum, and Bite Wafers in Pain Control Following First Arch Wire Placement in Orthodontic Patients. J Contemp Dent Pract 2020;21(4):416-420.

Source of support: Nil

Conflict of interest: None

in the field have suggested certain methods for coping with orthodontic pain. Such methods include prescribing nonsteroidal anti-inflammatory drugs (NSAIDs), ${ }_{1}^{10,11}$ anesthetic gels, ${ }^{12}$ mediated wax ${ }^{13}$ the application of low-level laser therapy to the periodontal tissues, ${ }^{14}$ transcutaneous electrical nerve stimulation (TENS), ${ }^{15}$ and vibrating stimulation of the PDL. ${ }^{16}$ In addition, nondrug modalities of controlling pain include using plastic wafers or chewing gum that have been suggested in dealing with the side effects of NSAIDs, such as stomach problems, thrombocytopenia, allergic reactions, increased blood pressure, and many other adverse reactions. ${ }^{17,18}$ 
Using plastic wafers or sugar-free chewing gum affects orthodontic pain control by temporarily displacing the teeth and loosening the tightly grouped PDL fibers enough to allow blood flow through compressed areas, which prevents inflammation and edema, and relieves pain and discomfort. ${ }^{17,19}$ It was the purpose of this study to investigate the effectiveness of using bite wafers and chewing gum in relieving pain after the activation of the first arch wire among Saudi orthodontic patients, and evaluating them in comparison with using ibuprofen. In addition to that, another important purpose was to investigate the effect of the nondrug pain control methods on the frequency of orthodontic appliance breakage.

\section{Materials and Methods}

A randomized clinical study was conducted at the Department of Orthodontics, College of Dentistry, King Saud University, Riyadh, Saudi Arabia. The study was approved by the Institutional Review Board (IRB), King Saud University [E-17-2716], and the College of Dentistry Research Center (CDRC), King Saud University [FR 0423]. The sample consisted of 105 female patients aged 15-35 years, who were scheduled to be fitted with fixed orthodontic appliances. The 0.016-inch nickel-titanium arch wires were fitted on the maxillary and mandibular arches of all patients during their first visit. The subjects were selected based on the following inclusion criteria: mild (1-4 mm) dental crowding according to the Little's Irregularity Index, ${ }^{20}$ no planned extraction, and only interproximal stripping performed to manage the crowding. On the other hand, patients with systemic periodontal disease, having undergone previous orthodontic therapy, and those with a history of hypersensitivity to ibuprofen were not included in the study. Likewise, pregnant patients and those receiving analgesic therapy were excluded from the present study. All procedures were explained to the patients and their parents and a written consent form was signed before starting the orthodontic treatment. The investigator ensured the anonymous identity of study participants and data were kept protected to ensure confidentiality and privacy of information. The study complies with the Helsinki Declaration.

The patients were randomly classified into three groups of 35 each, using a computer-generated random assignment program that was concealed from the investigator. The patients in each group received one of the following treatments immediately after first arch wire placement, and every 8 hours for 1 week as necessary: ibuprofen $(400 \mathrm{mg})$, horseshoe-shaped hard viscoelastic bite wafers of four different flavors (Dentakit Company), and sugar-free chewing gum (Trident White Spearmint Sugar Free Gum, Mondelez International Group, East Hanover, USA). The patients who received the bite wafers and chewing gum were instructed to chew for only 5 minutes every 8 hours as needed for 1 week. Also, they were informed that they could take $400 \mathrm{mg}$ of ibuprofen as a backup medication if the first two methods proved ineffective, and were instructed to keep record of how much, if any, ibuprofen was taken. A visual analog scale (VAS) was given to the patients to record their pain perception while biting, chewing, and fitting anterior and posterior teeth. The patients recorded their pain perception at the seven intervals: 2 hours, 6 hours, bedtime, 24 hours, 2 days, 3 days, and 7 days following first arch wire placement. This VAS is a $10-\mathrm{cm}$ line, with both ends defined as the extreme limits of the parameter to be measured (symptoms, pain, and health). ${ }^{21}$ All participants were asked to respond and return the VAS, as well as they were asked to report any incident of detached brackets while using nondrug methods at their next routine adjustment appointment.

\section{Statistical Analysis}

The three groups using different pain relief methods were classified according to a computer-generated random assignment program to achieve the randomization strategy. The Shapiro-Wilk test was used to confirm the normal distribution of variables. The $G^{*}$ Power software analysis was used to calculate the statistical power and estimate sample size for the three groups. At significance level $(\alpha)$ equals to 0.05 with estimated effect size $=0.4$ and power $92 \%$, the sample size for each group should be at least 30 subjects to achieve study objectives. The differences between the groups (pain relief methods at different time intervals) were analyzed using the one-way analysis of variance (ANOVA) and Tukey tests to determine if there was any statistical significance. In addition, a repeated measurement was used within each method to analyze the time interval effect. All statistical analyses were performed using the SPSS software package (Version 22, SPSS Inc., Chicago, IL, USA).

\section{Results}

There was a total of 15 dropout patients in the present study. Five subjects from each group were excluded from the study either because of the use of backup medication for the chewing gum and wafer groups or because some patients failed to return the given VAS with their pain perception. A total of 90 subjects with 30 in each group remained in the study. Descriptive statistics presenting mean values and standard deviations were used to report the individuals' age, pain perception values at 2 hours, 6 hours, bedtime, 24 hours, 2 days, 3 days, and 7 days after first arch wire fitting among the three different groups as shown in Table 1. The ANOVA at the 0.05 level demonstrated no significant differences in pain perception at any time interval among the groups (Table 1). Figure 1 illustrates the pain perception mean values at each time interval for the three groups. No clinical or statistical differences were found between the groups ( $p=0.68, p<0.05$ ). According to the chart, the pain score was at its highest level at bedtime and/or at 24 hours among different groups, and the pain perception finding at different time intervals using each pain relief method (ibuprofen, wafers, and chewing gum) was statistically significant when repeated measurement was used ( $p=0.000, p<0.05$ ) (Tables 2 and 3). Although four subjects reported an incident of detached brackets at the next routine visit (two from the chewing gum group, one from the ibuprofen group, and one from the wafer group), ANOVA results demonstrate that no clinically or statistically significant differences on bracket detachment were observed between the groups $(p=0.20, p<0.05)$ (Table 1).

\section{Discussion}

This randomized clinical study was conducted to investigate the effectiveness of using bite wafers and chewing gum in comparison with ibuprofen use in relieving pain following the first activation of fixed orthodontic appliances among Saudi orthodontic patients. Only female subjects were included in the study to rule out any gender-dependent variability in the sample, since some differences in the pain experience between males and females have been reported. ${ }^{9}$ The results showed that there is no clinically or statistically significant difference in pain perception at any time interval among the groups. This finding is consistent with the results of several researchers who conducted randomized clinical trials and concluded that sugar-free chewing gum and plastic wafers are effective as nondrug methods in alleviating pain induced by 
Table 1: Descriptive statistics with mean values and standard deviations reporting the individuals' age, pain perception values at different time interval, bracket detachment incidence among the three groups, and analysis of variance (ANOVA) results

\begin{tabular}{|c|c|c|c|c|}
\hline & Pain relief methods & Mean & Std. deviation & $p$ value* \\
\hline \multirow[t]{3}{*}{ Age } & Ibuprofen & 24.65 & 6.12 & - \\
\hline & Wafer & 21.75 & 7.38 & \\
\hline & Chewing gum & 25.90 & 6.99 & \\
\hline \multirow[t]{3}{*}{2 hours } & Ibuprofen & 3.88 & 1.52 & 0.66 \\
\hline & Wafer & 3.53 & 1.35 & \\
\hline & Chewing gum & 3.50 & 1.50 & \\
\hline \multirow[t]{3}{*}{6 hours } & Ibuprofen & 4.50 & 1.73 & 0.66 \\
\hline & Wafer & 4.08 & 1.34 & \\
\hline & Chewing gum & 4.10 & 1.84 & \\
\hline \multirow[t]{3}{*}{ Bedtime } & Ibuprofen & 5.08 & 1.73 & 0.63 \\
\hline & Wafer & 4.93 & 1.01 & \\
\hline & Chewing gum & 4.68 & 1.13 & \\
\hline \multirow[t]{3}{*}{24 hours } & Ibuprofen & 5.08 & 1.61 & 0.17 \\
\hline & Wafer & 4.36 & 1.18 & \\
\hline & Chewing gum & 4.18 & 1.88 & \\
\hline \multirow[t]{3}{*}{2 days } & Ibuprofen & 3.25 & 1.25 & 0.40 \\
\hline & Wafer & 2.60 & 1.43 & \\
\hline & Chewing gum & 2.98 & 1.78 & \\
\hline \multirow[t]{3}{*}{3 days } & Ibuprofen & 2.10 & 1.17 & 0.52 \\
\hline & Wafer & 1.65 & 1.31 & \\
\hline & Chewing gum & 2.05 & 1.54 & \\
\hline \multirow[t]{3}{*}{7 days } & Ibuprofen & 0.95 & 0.83 & 0.80 \\
\hline & Wafer & 0.80 & 1.06 & \\
\hline & Chewing gum & 1.00 & 1.08 & \\
\hline \multirow[t]{3}{*}{ Breakage } & Ibuprofen & 0.05 & 0.22 & 0.20 \\
\hline & Wafer & 0.05 & 0.22 & \\
\hline & Chewing gum & 0.10 & 0.20 & \\
\hline
\end{tabular}

${ }^{*}$ One-way repeated measurement analysis of variance (ANOVA) at the 0.05 level

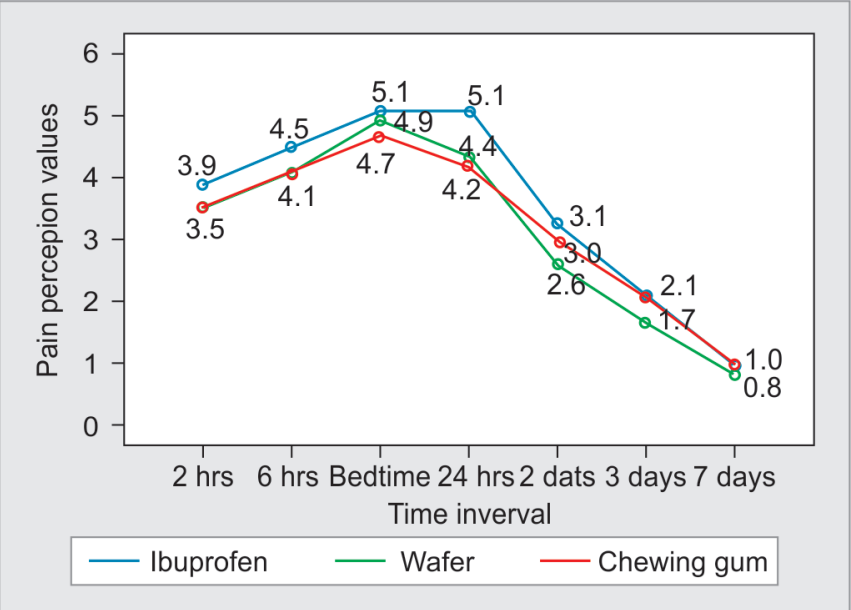

Fig. 1:The pain perception mean values at each time interval in the three groups showed that the pain scores were slightly higher with maximum intensity at bedtime and/or at 24 hours among different groups

the placement of orthodontic appliances. ${ }^{17,22-25} \mathrm{~A}$ similar result was found with another study by Ireland et al., ${ }^{26}$ who indicate that the use of sugar-free chewing gum may reduce the level of ibuprofen
Table 2: Mean pain perception findings at different time intervals and their overlap with highest intensity at bedtime and/or at 24 hours among different groups

\begin{tabular}{lll}
\hline Time intervals & Mean & Std. deviation \\
\hline 2 hours & 3.63 & 1.44 \\
6 hours & 4.23 & 1.63 \\
Bed time & 4.90 & 1.31 \\
24 hours & 4.53 & 1.60 \\
2 days & 2.94 & 1.50 \\
3 days & 1.93 & 1.34 \\
7 days & 0.92 & 0.98 \\
\hline
\end{tabular}

Table 3: Repeated measurement results showing no statistical differences between pain relief methods (ibuprofen, wafers, and chewing gum) while the pain perception findings at different time intervals within each pain relief method was statistically significant

\begin{tabular}{|c|c|c|c|c|}
\hline Variables & & & Means $\pm S D$ & Sig.* \\
\hline \multirow{2}{*}{\multicolumn{2}{|c|}{ Time intervals }} & $\begin{array}{l}\text { Mean increase } \\
\text { from baseline to } \\
\text { bedtime }\end{array}$ & $1.27 \pm 1.36$ & 0.000 \\
\hline & & $\begin{array}{l}\text { Mean decrease } \\
\text { from bedtime to } \\
7 \text { days }\end{array}$ & $3.98 \pm 1.33$ & \\
\hline \multirow[t]{6}{*}{$\begin{array}{l}\text { Pain relief } \\
\text { methods }\end{array}$} & Ibuprofen & $\begin{array}{l}\text { Mean increase } \\
\text { from baseline to } \\
\text { bedtime }\end{array}$ & $1.2 \pm 1.62$ & 0.678 \\
\hline & & $\begin{array}{l}\text { Mean decrease } \\
\text { from bedtime to } \\
7 \text { days }\end{array}$ & $4.13 \pm 1.28$ & \\
\hline & Wafer & $\begin{array}{l}\text { Mean increase } \\
\text { from baseline to } \\
\text { bedtime }\end{array}$ & $1.4 \pm 1.18$ & \\
\hline & & $\begin{array}{l}\text { Mean decrease } \\
\text { from bedtime to } \\
7 \text { days }\end{array}$ & $4.13 \pm 1.03$ & \\
\hline & $\begin{array}{l}\text { Chewing } \\
\text { gum }\end{array}$ & $\begin{array}{l}\text { Mean increase } \\
\text { from baseline to } \\
\text { bedtime }\end{array}$ & $1.18 \pm 1.31$ & \\
\hline & & $\begin{array}{l}\text { Mean decrease } \\
\text { from bedtime to } \\
7 \text { days }\end{array}$ & $3.68 \pm 1.10$ & \\
\hline
\end{tabular}

*Sig., approximate significance, where $p$ value at 0.05 level

usage after initial orthodontic fixed appliance placement and at the first arch wire change. Furthermore, the pain experienced at bedtime and at 24 hours post-procedure among different groups in the present study was found to be slightly higher with maximum intensity, indicating that the overall difference in pain perception between the three methods was not statistically significant, but between time intervals within each pain relief method was statistically significant. A similar finding has been reported by several studies. ${ }^{17,23}$ One study reported that the pain reaches maximum intensity in 2 days. ${ }^{9}$ The discrepancy in this finding among the different studies can be potentially attributed to sample size, different ethnic background of the subjects, and the different environmental factors affecting pain perception. ${ }^{27}$

The effect of plastic wafer and/or chewing gum use on the frequency of orthodontic appliance breakage was another measure that was investigated in this study. For standard cases, the 
orthodontists instruct their patients to avoid using chewing gums in order to prevent detachment of the brackets and the gum otherwise sticking to the brackets. However, in the present study, one of the objectives was to assess the possibility of bracket detachment by using different methods in order to relieve expected orthodontic pain. Furthermore, the patients in the experimental group receiving chewing gum were instructed to chew for not more than 5 minutes every 8 hours when needed for 1 week in order to avoid the risk of bracket detachment. If bracket detachment occurred, the patient was to contact the clinic immediately for an appointment to replace the loose bracket. The results suggest that there is no clinically or statistically significant difference in appliance breakage frequency between the two groups compared to patients using ibuprofen only. This finding was consistent with the conclusion of several clinical trials conducted by Ireland et al. ${ }^{26}$ and Benson et al., ${ }^{28}$ showing that chewing gum use had no significant effect on the number of appliance breakages. The four cases reporting an incident of detached brackets could be attributed to other reasons such as biting on hard objects or poor bracket bonding. Limitations of the study include the relatively small sample size and the gender limitation to female subjects only. Therefore, further studies are required to increase the sample size and include male sample in order to study the gender effect.

\section{Conclusion}

In conclusion, the use of bite wafers and sugar-free chewing gum was effective for the relief of pain resulting from the first activation of fixed orthodontic appliances. The results were compared to ibuprofen use effectiveness at all time intervals among Saudi orthodontic patients. In addition, no clinically or statistically significant differences on bracket detachment were found between the studied groups.

\section{ACKnOWLedgments}

This work has not been published previously and is not under consideration by another journal. The author is indebted to Mr Nasr Al-Maflehi for his help and advice on the statistical work.

\section{References}

1. Shenoy N, Shetty S, Ahmed J, et al. The pain management in orthodontics. J Clin Diagn Res 2013;7(6):1258-1260. DOI: 10.7860/ JCDR/2013/4860.3036.

2. Chow J, Cioffi I. Pain and orthodontic patient compliance: a clinical perspective. Semin Orthod 2018;24(2):242-247. DOI: 10.1053/ j.sodo.2018.04.006.

3. Sandhua SS, Leckie G. Orthodontic pain trajectories in adolescents: between-subject and within-subject variability in pain perception. Am J Orthod Dentofacial Orthop 2016;149(4):491-500. DOI: 10.1016/ j.ajodo.2015.10.020.

4. Gameiro GH, Schultz C, Trein MP, et al. Association among pain, masticatory performance, and proinflammatory cytokines in crevicular fluid during orthodontic treatment. Am J Orthod Dentofacial Orthop 2015;148(6):967-973. DOI: 10.1016/j.ajodo.2015.05.029.

5. Kafle D, Rajbhandari A. Anticipated pain and pain experience among orthodontic patients: is there any difference? Kathmandu Univ Med J 2012;38(2):71-73. DOI: 10.3126/kumj.v10i2.7348.

6. Sandhu SS, Cheema MS, Khehra HS. Comparative effectiveness of pharmacologic and nonpharmacologic interventions for orthodontic pain relief at peak pain intensity: a Bayesian network meta-analysis. Am J Orthod Dentofacial Orthop 2016;150(1):13-32. DOI: 10.1016/ j.ajodo.2015.12.025.
7. Campos MJ, Fraga MR, Raposo NR, et al. Assessment of pain experience in adults and children after bracket bonding and initial archwire insertion. Dental Press J Orthod 2013;18(5):32-37. DOI: 10.1590/S2176-94512013000500007.

8. Sergl HG, Klages U, Zentner A. Pain and discomfort during orthodontic treatment: causative factors and effects on compliance. Am J Orthod Dentofacial Orthop 1998;114(6):684-691. DOI: 10.1016/ S0889-5406(98)70201-X.

9. Sandhu SS, Sandhu J. A randomized clinical trial investigating pain associated with superelastic nickel-titanium and multistranded stainless steel arch wires during the initial leveling and aligning phase of orthodontic treatment. J Orthod 2013;40(4):276-285. DOI: 10.1179/1465313313Y.0000000072.

10. Patel S, McGorray SP, Yezierski R, et al. Effects of analgesics on orthodontic pain. Am J Orthod Dentofacial Orthop 2011;139(1): e53-e58. DOI: 10.1016/j.ajodo.2010.07.017.

11. Shetty N, Patil AK, Ganeshkar SV, et al. Comparison of the effects of ibuprofen and acetaminophen on PGE2 levels in the GCF during orthodontic tooth movement: a human study. Prog Orthod 2013;14(1):6. DOI: 10.1186/2196-1042-14-6.

12. Kwong TS, Kusnoto B, Viana G, et al. The effectiveness of Oraqix versus TAC (a) for placement of orthodontic temporary anchorage devices. Angle Orthod 2011;81(5):754-759. DOI: 10.2319/020811-91.1.

13. Eslamian L, Borzabadi-Farahani A, Edini HZ, et al. The analgesic effect of benzocaine mucoadhesive patches on orthodontic pain caused by elastomeric separators, a preliminary study. Acta Odontol Scand 2013;71(5):1168-1173. DOI: 10.3109/00016357.2012.757358.

14. Eslamipour F, Motamedian SR, Bagheri F. Ibuprofen and low-level laser therapy for pain control during fixed orthodontic therapy: a systematic review of randomized controlled trials and metaanalysis. J Contemp Dent Pract 2017;18(6):527-533. DOI: 10.5005/ jp-journals-10024-2078.

15. Kasat V, Gupta A, Ladda R, et al. Transcutaneous electric nerve stimulation (TENS) in dentistry- a review. J Clin Exp Dent 2014; 6(5):e562-e568. DOI: 10.4317/jced.51586.

16. Aljudaibi S, Duane B. Non-pharmacological pain relief during orthodontic treatment. Evid Based Dent 2018;19(2):48-49. DOI: 10.1038/sj.ebd.6401305.

17. Farzanegan F, Zebarjadb SM, Alizadeh S, et al. Pain reduction after initial arch wire placement in orthodontic patients: a randomized clinical trial. Am J Orthod Dentofacial Orthop 2012;141(2):169-173. DOI: 10.1016/j.ajodo.2011.06.042.

18. Bagnoli F, Rossetti A, Messina G, et al. Treatment of patent ductus arteriosus (PDA) using ibuprofen: renal side-effects in VLBW and ELBW newborns. J Matern Fetal Neonatal Med 2013;26(4):423-429. DOI: 10.3109/14767058.2012.733775.

19. Ireland AJ, Ellis $P$, Jordan $A$, et al. Chewing gum vs ibuprofen in the management of orthodontic pain, a multi-centre randomized controlled trial - the effect of anxiety. J Orthod 2017;44(1):3-7. DOI: 10.1080/14653125.2016.1277317.

20. Little RM. The irregularity index: a quantitative score of mandibular anterior alignment. Am J Orthod Dentofacial Orthop 1975;68(5): 554-563. DOI: 10.1016/0002-9416(75)90086-X.

21. Streiner DL, Norman GR, Cairney J. Health measurement scales: a practical guide to their development and use. 5th ed., New York: Oxford University Press; 2015.

22. Mangnall LA, Dietrich T, Scholey JM. A randomized controlled trial to assess the pain associated with the debond of orthodontic fixed appliances. J Orthod 2013;40(3):188-196. DOI: 10.1179/1465313313Y.0000000045.

23. Azeem M, Khan DI, Jamal F, et al. Chewing gum for pain control following orthodontic separator placement. J World Federation Orthod 2018;7(3):102-105. DOI: 10.1016/j.ejwf.2018.07.002.

24. Waheed-Ul-Hamid M, Ulhaq A, Mahmood HS, et al. Comparison between ibuprofen and chewing gum for orthodontic pain control. Pak Oral Dent J 2016;36(1):79-83.

25. Bayani S, Rostami S, Ahrari F, et al. A randomized clinical trial comparing the efficacy of bite wafer and low level laser therapy 
in reducing pain following initial arch wire placement. Laser Ther 2016;25(2):121-129. DOI: 10.5978/islsm.16-OR-10.

26. Ireland AJ, Ellis P, Jordan A, et al. Comparative assessment of chewing gum and ibuprofen in the management of orthodontic pain with fixed appliances: a pragmatic multicenter randomized controlled trial. Am J Orthod Dentofacial Orthop 2016;150(2):220-227. DOI: 10.1016/j. ajodo.2016.02.018
27. Campbell CM, Edwards RR. Ethnic differences in pain and pain management. Pain Manag 2012;2(3):219-230. DOI: 10.2217/ pmt.12.7.

28. Benson PE, Razi RM, Al-Bloushi RJ. The effect of chewing gum on the impact, pain and breakages associated with fixed orthodontic appliances: a randomized clinical trial. Orthod Craniofac Res 2012;15(3):178-187. DOI: 10.1111/j.1601-6343.2012.01546.x. 